\title{
Impulse Blockade by Intraocular Tetrodotoxin During Optic Regeneration in Goldfish: HRP-EM Evidence that the Formation of Normal Numbers of Optic Synapses and the Elimination of Exuberant Optic Fibers Is Activity Independent
}

\author{
William Pär Hayes ${ }^{\mathrm{a}}$ and Ronald L. Meyer \\ Developmental Biology Center, and Department of Developmental and Cell Biology, University of California, Irvine, \\ California 92717
}

\begin{abstract}
Optic fibers and synapses labeled with HRP were counted in the primary optic innervation layer of tectum after continuously blocking visual impulse activity with TTX during regeneration. Normal numbers of optic and nonoptic fibers and synapses were found at both 30 and $60 \mathrm{~d}$, and key ultrastructural features of optic afferents such as fiber fasciculation, myelination, terminal clustering, synaptogenesis onto different classes of postsynaptic targets and general morphology were not notably affected by impulse blockade. These findings indicate that during regeneration the normal proliferation and elimination of optic fibers and the formation of normal numbers of optic synapses are not regulated by activity and are consistent with a pattern formation role for impulse activity rather than a trophic one.
\end{abstract}

Several recent studies have shown that the elimination of impulse activity by intraocular injection of the sodium channel blocker TTX disrupts the patterned distribution of nerve connections in the visual system of fish, frogs and mammals. In cats, TTX impulse blockade during postnatal development prevents the segregation of dorsal lateral geniculate (dLGN) fibers into ocular dominance columns in visual cortex (Chapman et al., 1986; Stryker and Harris, 1986) and interferes with the formation of On and Off center input, $X$ and $Y$ input, and binocularity in the dorsal lateral geniculate nucleus (dLGN) (Dubin et al., 1986). TTX also has been reported to block or delay the development of the refined retinotopy in the retinocollicular projection in rats (Fawcett et al., 1984; O'Leary et al., 1986). For the regenerating retinotectal projection of goldfish, impulse blockade with TTX inhibits the refinement of the retinotopic map in fish (Meyer, 1983, 1987; Schmidt and Edwards, 1983), as well as the formation of ocular dominance columns after 2 eyes are made to innervate the same tectum (Meyer, 1982; Boss and Schmidt, 1984; see also Reh and Constantine-

Received July 16, 1987; revised Aug. 15, 1988; accepted Aug. 29, 1988

This work was supported by PHS Grants NS 16319 and EY 06746 to R.L.M. and PHS Training Grant HD 07029 to W.P.H. Special thanks are due to Dr. R. D. Campbell, Dr. C. E. Ribak, and Dr. S. E. Fraser for encouragement and valuable discussions during the study and in the preparation of the manuscript. This work was submittcd by W.P.H. to the Department of Developmental and Cell Biology at the University of California, Irvine, in partial fulfillment of the requirements for the degree of Doctor of Philosophy.

Correspondence should be addressed to Dr. R. L. Meyer, Developmental Biology Center, University of California, Irvine, Irvine, CA 92717.

Present address: National Institutes of Health, Child Health and Human Development, Laboratory of Developmental Neurobiology, Building 36, Room 2A21, Bethesda, Maryland 20892.

Copyright (C) 1989 Society for Neuroscience $0270-6474 / 89 / 041414-10 \$ 02.00 / 0$
Paton, 1985, for data on frogs). These findings have been interpreted to mean that impulse activity plays a selective and critical role in the refinement of synaptic connections during both development and regeneration (Stent, 1973; Prestige and Willshaw, 1975; Changeux and Danchin, 1976; Willshaw and von der Malsburg, 1976; Whitelaw and Cowan, 1981; reviewed by Harris, 1981).

The ultrastructural correlates of these effects of activity are largely unknown. While it has been shown that impulse blockade with TTX does not prevent synapse formation (Harris, 1980), it is not known, for example, whether activity regulates the number or maturation of synapses. There is some suggestion that it may. In the developing mammalian visual system, spine (Riccio and Matthews, 1985a; see also Van Huizen et al., 1985) and synapse (Riccio and Matthews, 1985b) formation are reduced in visual cortex and the maturation of optic synapses in dLGN is prevented or delayed by TTX blockade (Kalil et al., 1986). However, these developmental studies are open to multiple interpretations. Rather than representing a direct effect of activity on synaptic patterning, they may instead reflect a role for activity in neuronal maturation or in the regulation of cell death (Nelson and Brenneman, 1982). These studies also suffered from the quantitative limitations imposed by sampling unlabeled synapses in a complex neuropil.

The retinotectal system of the adult goldfish offers the possibility of testing the effects of impulse activity without these developmental complications. In the goldfish, the neurons are obviously well differentiated and cell death does not occur during optic nerve regeneration (Edwards and Grafstein, 1983). Equally important is the recent development of a labeling method for goldfish that allows identification of virtually all optic fibers and synapses during regeneration. Using this method, we asked whether TTX blockade alters the number of synapses or the recently described fiber remodeling that occurs during regeneration (Hayes and Meyer, 1989). Neither was detectably altered, suggesting that, in this system, impulse activity plays a selective role in patterning. The results of the present study were previously reported in preliminary form (Hayes and Meyer, 1986).

\section{Materials and Methods}

Detailed descriptions of the HRP cold-fill labeling protocol and laminar analysis of fiber and synapse numbers have been presented elsewhere (Hayes and Meyer, 1988a-c, 1989). What follows is a description of the TTX injection protocol and a summary of the other methods.

$T T X$ injections to eliminate impulse activity. One day after optic nerve crush, fish were injected with $50 \mathrm{nl}$ of citrate-buffered $1.2 \mathrm{mM}$ TTX into 
the left eye at the cdge of the dorsal sclera using a calibrated Hamilton syringe. These injections were repeated every $2.5 \mathrm{~d}$ for either 30 or 60 d. This regimen is more stringent than the one that was shown by electrophysiological recording to continuously block spontaneous and visually evoked impulse activity in the nerve and on tectum (Meyer 1982,1983 ). As an injection control, a second group of fish with crushed left optic nerves received citrate carrier buffer lacking TTX. The effec= tiveness of impulse blockade was also monitored by observing fish behavior. Fish with TTX injections showed a visual righting reflex seen as a slight upward tilt on the side of the injected eye.

HRP-EM labeling and histochemistry. Goldfish $(4.5-6.0 \mathrm{~cm})$ were anesthetized with tricaine and the left optic nerve crushed. The fish were then reared for 30 or $60 \mathrm{~d}$ at $19-21^{\circ} \mathrm{C}$. Anesthetized fish were labeled with HRP by enucleating the TTX- or sham-injected eye and sucking the optic nerve stump into segments of polyethylene tubing sealed at one end and containing a $25-30 \%$ solution of HRP (Type II, Sigma). Upon recovering, fish were maintained at $5-7^{\circ} \mathrm{C}$ for $48-72 \mathrm{hr}$. Fish were then anesthetized and perfused transcardially using tricaine in fish Ringer's followed by aldehyde fixation. Sections were cut using a vibrating microtome and reacted histochemically using diaminobenzidine (DAB) as the chromogen (Adams, 1981).

Labeled tissue was prepared for electron microscopy as described elsewhere (Hayes and Meyer, 1988a-c, 1989). Ultrathin sections always contained the entire primary retinotectal layer (S, SO, and SFGS laminae), as well as the overlying marginal fiber lamina (SM) and underlying central gray lamina (SGC) (for laminar nomenclature, see Stürmer and Easter, 1984; Hayes and Meyer, 1988a-c, 1989).

Laminar analysis of synapse and fiber numbers. Electron micrographs were taken from equivalent anteromedial tectal regions in all animals. Radial sample columns consisting of overlapping $\times 18,000$ micrographs were constructed through the S-SO-SFGS as described by Hayes and Meyer (1988c, 1989).

The sample columns were divided into $30-40$ rectangular bins, 14 $\mu \mathrm{m}$ wide and $3 \mu \mathrm{m}$ deep, and labeled synapses, labeled unmyelinated fibers, labeled myelinated fibers, unlabeled synapses, and unlabeled myelinated fibers were marked and tabulated in each bin. These counts per bin were used to construct depth profile distributions and thickness measurements of the optic laminae. Mean numbers of profiles were derived by summing total numbers per sample column and pooling data from thcsc columns as described in Hayes and Meyer (1989). The criteria for identifying profiles and laminar boundaries are detailed elsewhere (Hayes and Meyer, 1988a, c, 1989). A number of statistical tests of significance were carried out (see Hayes and Meyer, 1989).

\section{Results}

This study consisted of 3 fish (XREG6, XREG7, XREG8) examined at $30 \mathrm{~d}$ and another 3 fish (XREG10, XREG11, XREG12) at $60 \mathrm{~d}$. In addition, one fish each at $30 \mathrm{~d}$ (XREG5) and $60 \mathrm{~d}$ (XREG9) served as sham-injection controls, as did uninjected fish from a previous study (Hayes and Meyer, 1989).

\section{Light microscopy of optic fibers regenerating under TTX}

Vibratome sections cut coronally (data not shown) showed that labeled optic afferents innervated the entire anterior-posterior and medial-lateral extent of the primary retinotectal innervation layer (S-SO-SFGS) in a dense and uniform fashion at 30 and $60 \mathrm{~d}$ (see Hayes and Meyer, 1988b). Semithin plastic sections (data not shown) from the anteromedial tectum in different fish showed that the laminar distribution of labeled optic fibers was similar to that seen in normal fish and in fish regenerating with activity, including the absence of optic afferents in the intermediate optic fiber (SOi) lamina (see Hayes and Meyer, 1988b, 1989).

\section{Electron microscopy of optic fibers and synapses regenerating without activity}

The labeling of optic fibers and synaptic terminals in the S-SOSFGS of fish regenerating in the absence of activity was indistinguishable from that seen in sham-injected fish or in fish with nerves regenerating with activity (Hayes and Mcyer, $1988 \mathrm{a}-\mathrm{c}$, 1989). Optic profiles were densely filled with granular $D A B$ product in the $\mathrm{S}, \mathrm{SO}$, and $\mathrm{SFGS}$. Large numbers of fascicles containing many labeled fibers were seen in the SFGS at $30 \mathrm{~d}$ (Fig. 1), and these were reduced in size and contained fewer fibers by $60 \mathrm{~d}$ (Fig. 2). Synaptic terminals that formed in the absence of activity were typically grouped in clusters often in contact with or in proximity to optic fascicles at all times of regeneration (Figs. 2, 3A) just as seen with activity. HRP=labcled retinal terminals were observed which made the 4 types of synaptic contacts seen in normal fish, as well as the atypical, probably nascent synapses (Fig. $3 B$ ) seen previously during regeneration with activity (see Discussion in Hayes and Meyer, 1988b), indicating nerve impulses are not required for retinotectal synapse formation.

The sizes of optic terminals and the number of synapses they made appeared to be unaffected by impulse blockade (Hayes and Meyer, 1988a-c, 1989). Most were large, were filled with vesicles, and made multiple synaptic contacts. Synaptic contact length was also measured. These lengths were as follows: normal fish, $0.25 \pm 0.06 \mu \mathrm{m}(n=25,2$ fish); $30 \mathrm{~d}$ regeneration in the absence of activity, $0.25 \pm 0.05 \mu \mathrm{m}(n=25,2 \mathrm{fish})$, and $30 \mathrm{~d}$ regeneration with activity, $0.23 \pm 0.06 \mu \mathrm{m}(n=25,1$ fish $)$; and $60 \mathrm{~d}$ in the absence of activity, $0.25 \pm 0.05 \mu \mathrm{m}$ ( 2 fish, $n=25$ ) and $60 \mathrm{~d}$ regeneration with activity, $0.24 \pm 0.06 \mu \mathrm{m}$ (1 fish, $n$ $=25$ ). No significant differences in contact length were found between normal fish, fish regenerating with activity, and fish regenerating without activity.

\section{Quantitative spatiotemporal analysis of retinotectal regeneration in the absence of impulse activity}

Optic and nonoptic fiber and synapse numbers were determined as a function of tectal depth from the electron micrograph photomontages.

Depth profile of synapses and fibers. The depth profiles showed that the distribution of regenerating optic (labeled) and nonoptic (unlabeled) fibers and synapses was indistinguishable from that found for fish with activity during regeneration (data not shown; see Hayes and Meyer, 1989). Optic fibers and synapses regenerating under TTX were confined to their normal optic laminae in the S-SO-SFGS and were not observed in the SM, SOi, and upper SGC. Most labeled synapses were distributed in the upper two-thirds of the SFGS, while unlabeled synapses were proportionately greater than labeled synapse numbers in the nonoptic SOi lamina and deep half of the SFGS. Optic fiber depth profiles differed from those found for normal fish in the same way irrespective of the presence or absence of impulse activity during regeneration (data not shown; see Hayes and Meyer, 1989). The thickness of optic laminae, S-SO, SFGS, and S-SOSFGS was increased in the same manner as during regeneration with activity (Table 3 ).

Changes in fiber and synapse numbers during regeneration. Mean synapse counts in fish with nerves regenerating without activity showed that the numbers of labeled $(p>0.3)$, unlabeled $(p>0.25)$, and total $(p>0.3)$ synapses in the S-SO-SFGS were not statistically different from those seen in normal fish and in fish with nerves regenerating with activity (Table 1, Fig. 4A). In addition, the mean percentage of labeled synapses relative to total synapses in the S-SO-SFGS at 30 and $60 \mathrm{~d}$ without activity was virtually the same as that found when activity was present during regeneration (Table 1).

Fiber counts in the SFGS showed that during regeneration, 
Figure 1. Low-magnification electron micrograph of labeled optic fiber fascicles in the SFGS of a fish (XREG8) regenerating $30 \mathrm{~d}$ in the continuous absence of impulse activity. Note that optic fibers are all unmyelinated and form tight fascicles that lack intervening glial processes (see Hayes and Meyer, 1988b). Scale bar, $2 \mu \mathrm{m}$.

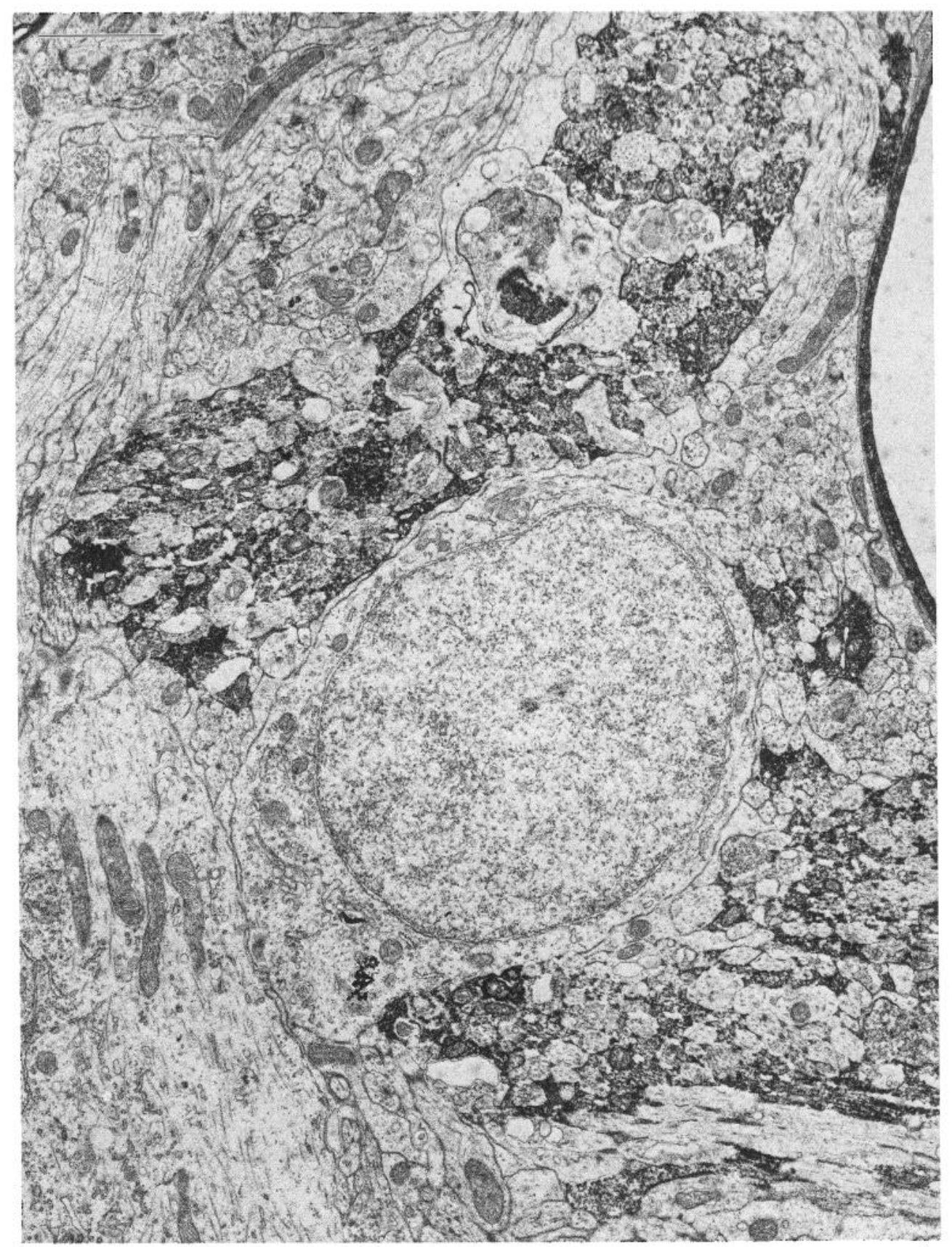

there was an approximately 10 -fold increase in the normal number of optic fibers at $30 \mathrm{~d}$ followed by a $50 \%$ decrease at $60 \mathrm{~d}$ whether or not impulse activity was eliminated (Table 2, Fig. $4 B)$. These differences were statistically significant $(p<0.005)$, whereas differences in unlabeled (nonoptic) fiber numbers were not $(p>0.25)$. The progessive remyelination of optic fibers was also unaffected by impulse blockade (Table 2).

Optic fiber fasciculation. Impulse blockade did not affect the tendency of optic fibers to be fasciculated in tectum during regeneration (Hayes and Meyer, 1988b). Over $80 \%$ of the optic fibers in the SFGS were contained in fascicles whether or not impulse activity was inhibited (Table 2).

There was, however, some suggestion of a difference in the way optic fibers were eliminated (Table 2). Optic fascicle counts in fish during regeneration with activity showed that the total number of optic fascicles per column was unchanged (Hayes and Meyer, 1989). But when impulses are eliminated, the total number of optic fascicles appears to be reduced between 30 and $60 \mathrm{~d}$, the difference being mainly in the number of fascicles containing fewer than 5 fibers (Table 2, Fig. 5; see also Fig. $9 B$ in Hayes and Meyer, 1989). In other respects, the changes in fasciculated optic fiber numbers appear to be the same as that seen during regeneration with activity.

\section{Discussion}

The principal finding of the present study is that blocking impulse activity during regeneration has no effect on numbers of optic fibers and synapses. Particularly noteworthy, the numbers 


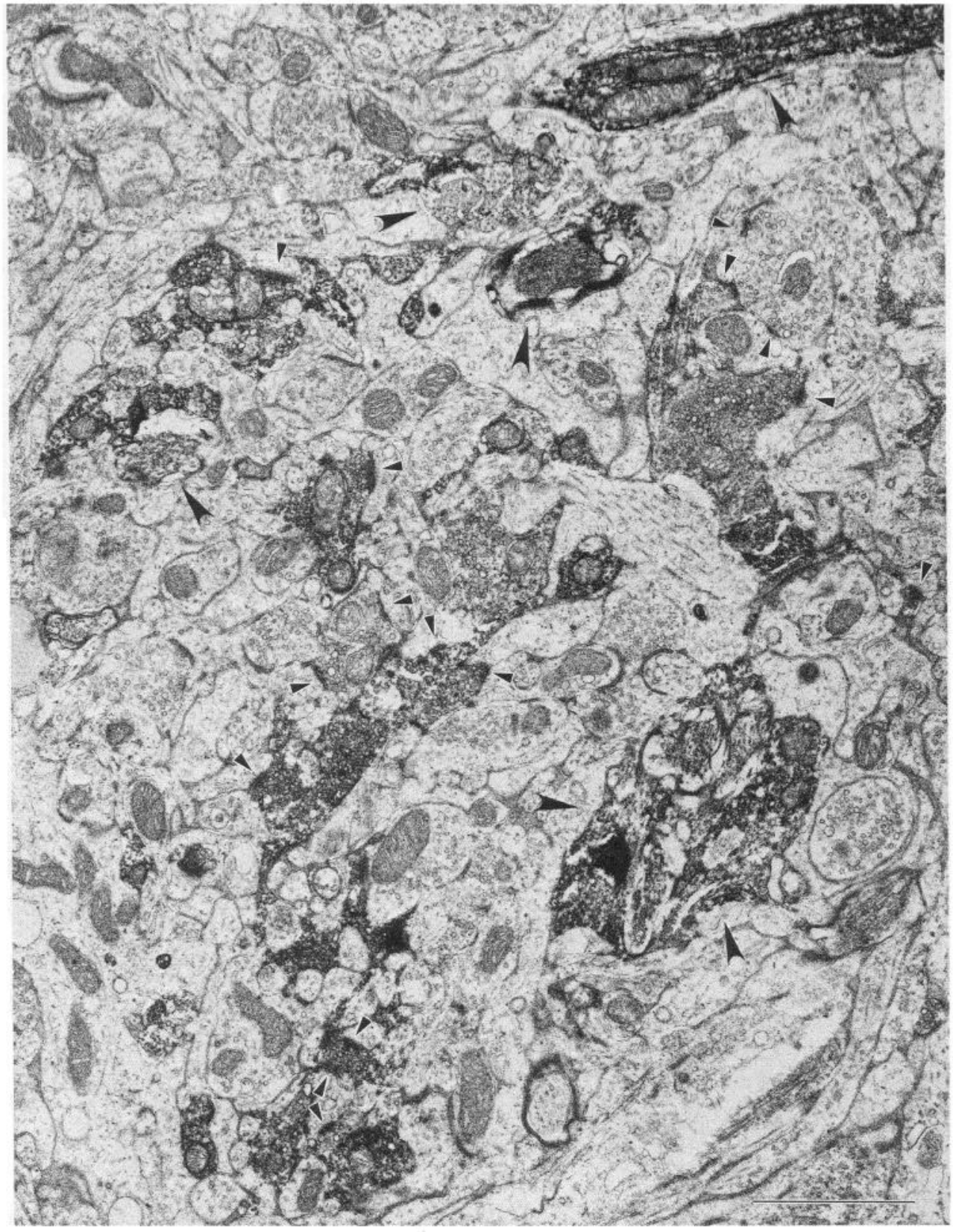

Figure 2. Low-magnification electron micrograph of labeled optic fibers and terminals in the SFGS of a fish (XREG11) regenerating $60 \mathrm{~d}$ in the continuous absence of impulse activity. Note that optic fibers are for the most part fasciculated (large arrowheads), and some labeled myelinated fibers are present. Note also that many optic synapses (small arrowheads) are made by optic terminals grouped in clusters, and clustered terminal profiles are often in direct contact with each other. Scale bar, $1 \mu \mathrm{m}$. of optic fibers in the SFGS increased 10-fold and then decreased by half during the interval that normally coincides with activitydependent map refinement.

\section{Optic synapse formation during neural impulse blockade}

The finding that normal numbers of optic synapses form in tectum during regeneration in the absence of impulse activity indicates that impulse-dependent neural transmission does not markedly regulate the time course of synaptogenesis or the numbers of synapses. The laminar analysis of synapses further showed that the laminar distribution of optic synapses, in particular the confinement of optic fibers to the S and SFGS laminae and their absence from the SO lamina, is activity independent, implying they are mediated by chemospecific cues (Sperry, 1963). Other previously described cytological features such as optic terminal clustering and the formation of synapses onto the 4 classes of postsynaptic profiles were not qualitatively altered (Hayes and Meyer, 1988b).

These findings are in agreement with previous studies that, on the basis of indirect measures, suggested that synaptogenesis proceeds normally under TTX blockade. Autoradiographic labeling indicated that silenced fibers reinnervated tectum on schedule and selectively invaded the optic laminae (Meyer, 1983). The size of the field potential evoked by nerve shock in TTXtreated fish during optic regeneration was reportedly also normal (Schmidt et al., 1983). An obvious caveat to these electrophysiological as well as the behavioral tests, however, is that these did not actually show that synapses were made without activity because the fish were allowed to recover from TTX for an estimated $18-24 \mathrm{hr}$ or more in order to carry out experiments.

The overall normalcy of synapse formation contrasts with reports that some selected phases of axoplasmic transport (Ed- 

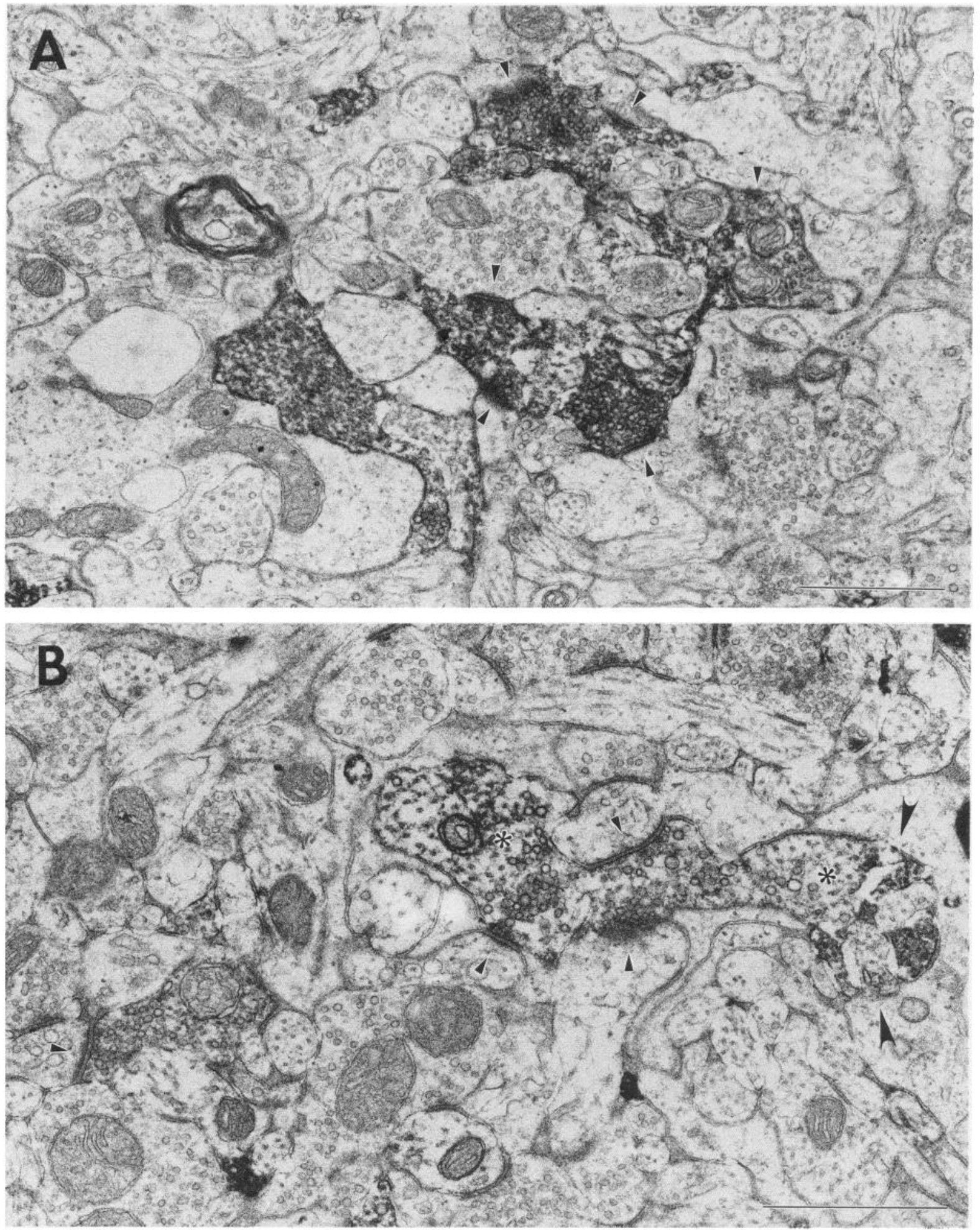

Figure 3. High-magnification electron micrographs showing optic synapses in the SFGS at 30 and $60 \mathrm{~d}$ regeneration in the continuous absence of impulse activity. A: $30 \mathrm{~d}$ TTX (XCREG8). Numerous labeled synapses (arrowheads) are made by optic fibers. B: $60 \mathrm{~d}$ TTX (XREG11). Several optic synapses (arrowheads) are made by a growth conelike process (asterisks) in contact with an optic fiber fascicle (large arrowhead) on the right. Note also the optic terminal making a synapse on the lower left. Scale bars, $1 \mu \mathrm{m}$.

wards and Grafstein, 1984, 1986; see also Riccio and Matthews, $1985 \mathrm{c})$ are inhibited and that the time of recovery of some behavioral responses (Edwards and Grafstein, 1983) in goldfish is delayed by TTX. The present findings lead to the suggestion that these effects are not a direct consequence of TTX regen- eration and initial synaptogenesis. They may instead be indirect consequences of disturbing the pattern of connections or blocking later maturational events.

The constancy in the number of both optic and nonoptic synapses also indicates that impulse blockade did not lead to 
A

Mean Synapse Numbers per column S-SO-SFGS

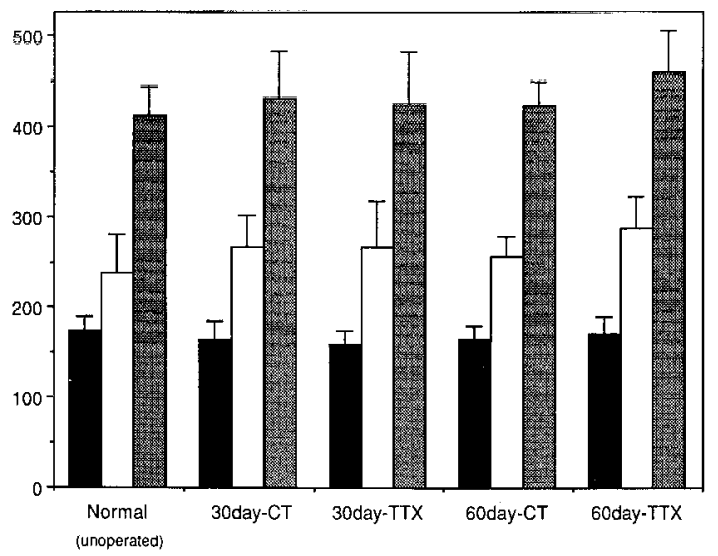

Regeneration
B

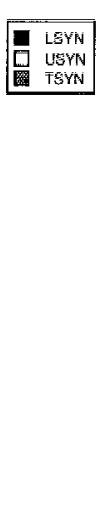

Figure 4. Histograms of mean numbers of total optic and nonoptic fibers and synapses in normal fish and fish regenerating in the presence or absence of impulse activity. The control data is the mean of the sample column data pooled from fish regenerating in the presence of activity (taken from Hayes and Meyer, 1989), and the sham-injection controls in the present study (see Tables 2 and 3 for data, and the number of columns and fish). A, Synapse numbers per column S-SO-SFGS: labeled (solid bar), unlabeled (open bar), total, i.e., labeled plus unlabeled (shaded bar). B, Fiber numbers per column SFGS (labels as in $A$ ).

substantial terminal sprouting as has been found using TTX in the developing and regenerating neuromuscular system (Brown and Ironton, 1977; reviewed in Thompson, 1985). This is perhaps not surprising since optic denervation does not appear to increase the number of nonoptic synapses (Murray and Edwards, 1982; Hayes and Meyer, 1988a, 1989), and the number of optic synapses per column is normal following compression of optic projections onto surgically halved tectum (Hayes and
Meyer, 1986, 1988c; see also Murray et al., 1982). This suggests that the number of synapses is fixed by the tectal cells and not readily modified by either activity or the number of afferent fibers.

The present finding that TTX blockade has no effect on synaptic contact length or numbers contrasts to the positive effects of impulse blockade on both synaptic numbers and size during mammalian optic development (Riccio and Matthews, 1985a,

Table 1. Summary of mean synapse numbers per sample column

\begin{tabular}{|c|c|c|c|c|}
\hline & $\begin{array}{l}\text { Labeled } \\
\text { synapses } \\
\text { (LSYN) }\end{array}$ & $\begin{array}{l}\text { Unlabeled } \\
\text { synapses } \\
\text { (USYN) }\end{array}$ & $\begin{array}{l}\text { Total } \\
\text { synapses } \\
\text { (TSYN) }\end{array}$ & $\begin{array}{l}\text { (LSYN/ } \\
\text { TSYN } \times \\
100) \%\end{array}$ \\
\hline \multicolumn{5}{|l|}{ Normal development ${ }^{a}$} \\
\hline$(n=5,3$ fish $)$ & $174 \pm 15$ & $238 \pm 42$ & $411 \pm 33$ & $42.6 \pm 6.0$ \\
\hline \multicolumn{5}{|l|}{30 d TTX injection regeneration ${ }^{b}$} \\
\hline$(n=4,3$ fish $)$ & $159 \pm 14$ & $266 \pm 50$ & $424 \pm 58$ & $37.7 \pm \mathbf{3 . 5}$ \\
\hline \multicolumn{5}{|l|}{$30 \mathrm{~d}$ control regeneration } \\
\hline$(n=7,4$ fish $)$ & $164 \pm 20$ & $267 \pm 34$ & $431 \pm 51$ & $37.9 \pm 2.5$ \\
\hline \multicolumn{5}{|l|}{$30 \mathrm{~d}$ sham injection regeneration ${ }^{d}$} \\
\hline $\begin{array}{l}(n=2,1 \text { fish }) \\
30 \mathrm{~d} \text { normal regeneration }{ }^{a}\end{array}$ & $160 \pm 30$ & $244 \pm 18$ & $403 \pm 48$ & $39.4 \pm 2.8$ \\
\hline$(n=5,3$ fish $)$ & $167 \pm 20$ & $283 \pm 48$ & $449 \pm 64$ & $37.3 \pm 2.4$ \\
\hline \multicolumn{5}{|l|}{$60 \mathrm{~d}$ TTX injection regeneration ${ }^{b}$} \\
\hline \multicolumn{5}{|l|}{$60 \mathrm{~d}$ control regeneration ${ }^{c}$} \\
\hline \multicolumn{5}{|l|}{$60 \mathrm{~d}$ sham injection regeneration ${ }^{d}$} \\
\hline \multicolumn{5}{|l|}{$60 \mathrm{~d}$ normal regeneration ${ }^{a}$} \\
\hline
\end{tabular}

a Data from Hayes and Meyer (1989).

${ }^{b}$ TTX injections every 2-3 d to continuously eliminate impulse transmission (see Materials and Methods).

Pooled normal regeneration and sham-injection data.

${ }^{d}$ Citrate carrier buffer injections intraocularly every $2-3 \mathrm{~d}$. 


\section{Mean Optic Fiber-Fascicle Numbers per column SFGS}

Figure 5. Graph of optic fiber fasciculation during regeneration. Mean number of fascicles per column SFGS: total (filled bar), fascicles with over 80 fibers (first open bar to the left of filled bar), with over 40 fibers (second open bar), with over 20 fibers (third open bar), with over 10 fibers (fourth open bar), with over 5 fibers (fifth open bar), with under 5 fibers (shaded bar). The control data is the mean of sample column data from the sham-injected fish (see Table 2 for the number of sample columns and fish used; see Hayes and Meyer, 1989 , for control fish that were not injected).

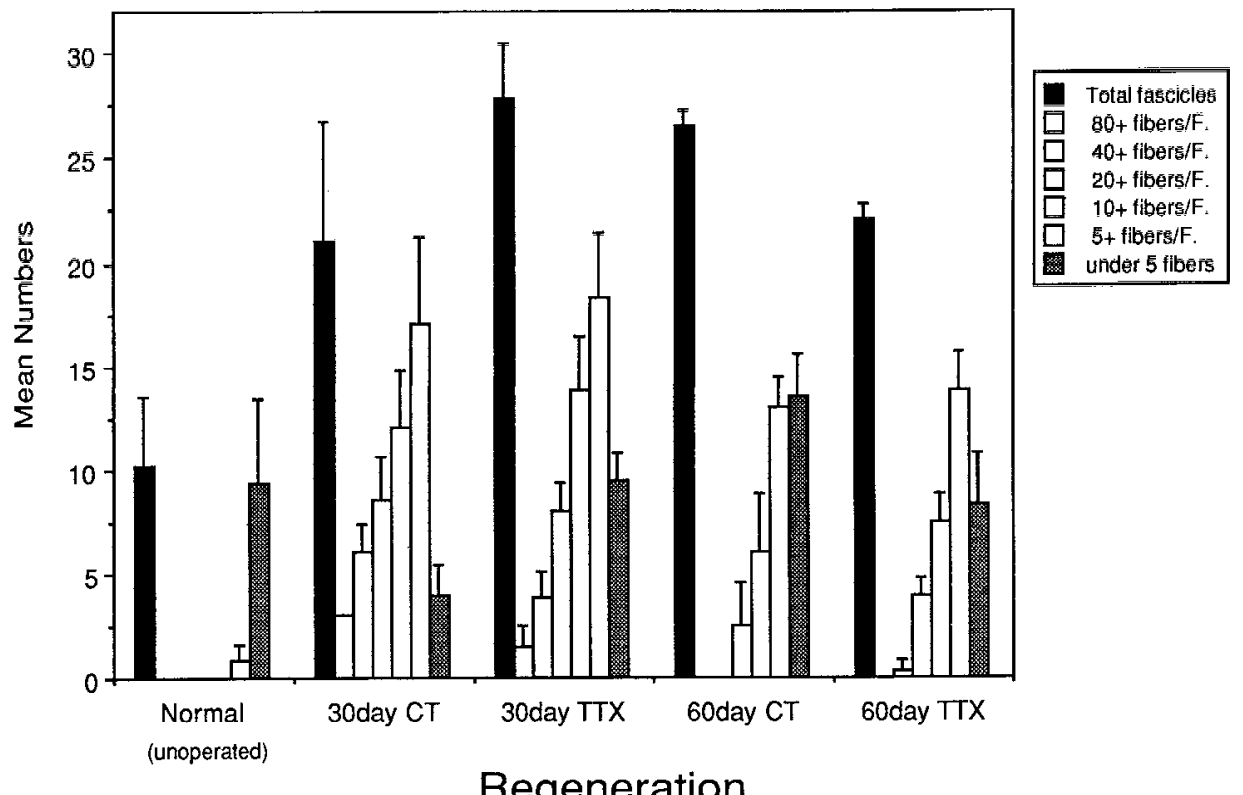

Regeneration b; Van Huizen et al., 1985; Kalil et al., 1986). These differences would be consistent with the idea that impulse activity plays a role in neuronal maturation during development (see Nelson and Brenneman, 1982) which is not necessary during regener- ation when neurons are mature. Evidence for this is that impulse elimination appears to retard the normal growth of neurons in development (Kuppermann and Kasamatsu, 1983; Kalil et al., 1986) but not in regeneration (Edwards and Grafstein, 1983).

Table 2. Summary of mean fiber numbers per sample column

\begin{tabular}{|c|c|c|c|c|c|c|c|c|}
\hline & $\begin{array}{l}\text { Labeled } \\
\text { fibers } \\
\text { (LFIB) }\end{array}$ & $\begin{array}{l}\text { Unlabeled } \\
\text { fibers } \\
\text { (UFIB) }\end{array}$ & $\begin{array}{l}\text { Myelinated } \\
\text { LFIB }\end{array}$ & $\begin{array}{l}\% \text { Myelinated } \\
\text { LFIB }\end{array}$ & $\begin{array}{l}\text { LFIB in } \\
\text { fascicles }\end{array}$ & $\begin{array}{l}\% \text { LFIB in } \\
\text { fascicles }\end{array}$ & $\begin{array}{l}\text { Labeled } \\
\text { fascicles }\end{array}$ & $\begin{array}{l}\text { Mean } \\
\text { LFIB per } \\
\text { fascicle }\end{array}$ \\
\hline $\begin{array}{l}\text { Normal development }{ }^{a} \\
\quad(n=5,3 \text { fish })\end{array}$ & \multicolumn{7}{|c|}{ Normal development ${ }^{a}$} & $2.9 \pm 0.5$ \\
\hline \multicolumn{9}{|l|}{$\begin{array}{l}30 \text { d TTX injection } \\
\text { regeneration }\end{array}$} \\
\hline$(\mathrm{n}=4,3$ fish $)$ & $571 \pm 131$ & $31 \pm 11$ & $<\mathbf{1 0}$ & $<2$ & $507 \pm 125$ & $88.5 \pm 2.8$ & $27.8 \pm 2.6$ & $18.1 \pm 3.3$ \\
\hline \multicolumn{9}{|l|}{$30 \mathrm{~d}$ control regeneration ${ }^{c}$} \\
\hline \multicolumn{9}{|l|}{$\begin{array}{l}30 \mathrm{~d} \text { sham injection } \\
\text { regeneration }\end{array}$} \\
\hline$(n=2,1$ fish $)$ & $713 \pm 48$ & $48 \pm 18$ & $<10$ & $<2$ & $632 \pm 59$ & $88.6 \pm 2.3$ & $21.0 \pm 5.7$ & $30.9 \pm 5.4$ \\
\hline $\begin{array}{l}30 \mathrm{~d} \text { normal regeneration } \\
(n=5,3 \text { fish })\end{array}$ & $460 \pm 93$ & $27 \pm 3$ & $1 \pm 3$ & $0.3 \pm 0.6$ & $400 \pm 94$ & $86.4 \pm 4.0$ & $23.6 \pm 6.0$ & $17.8 \pm 6.9$ \\
\hline \multicolumn{9}{|l|}{$\begin{array}{l}60 \mathrm{~d} \text { TTX injection } \\
\text { regeneration }\end{array}$} \\
\hline $\begin{array}{l}(\mathbf{n}=\mathbf{5}, \mathbf{3} \text { fish }) \\
60 \mathrm{~d} \text { control regeneration }\end{array}$ & $252 \pm 23$ & $25 \pm 5$ & $\mathbf{5 3} \pm \mathbf{5}$ & $21 \pm 2$ & $214 \pm 11$ & $85.2 \pm 8.7$ & $22.0 \pm 0.8$ & $9.6 \pm 0.2$ \\
\hline $\begin{array}{l}(n=7,4 \text { fish }) \\
60 \text { d sham injection } \\
\text { regeneration }{ }^{d}\end{array}$ & $230 \pm 35$ & $25 \pm 8$ & $20 \pm 13$ & $9 \pm 6$ & $198 \pm 38$ & $85.8 \pm 6.1$ & $25.9 \pm 5.5$ & $7.8 \pm 1.4$ \\
\hline$(n=2,1$ fish $)$ & $226 \pm 36$ & $24 \pm 1$ & $35 \pm 0$ & $15.5 \pm 0$ & $191 \pm 57$ & $83.8 \pm 11.7$ & $26.5 \pm 0.7$ & $7.3 \pm 2.3$ \\
\hline $\begin{array}{l}60 \mathrm{~d} \text { normal regeneration }{ }^{a} \\
(n=5,3 \mathrm{fish})\end{array}$ & $231+39$ & $25+10$ & $14+9$ & +4 & $200+37$ & $866+43$ & $256+67$ & $80+12$ \\
\hline$(n-J, 5$ ISII) & $201+37$ & $25 \pm 10$ & $14 \pm 9$ & $0 \pm 4$ & 20013 & $00.0 \pm 4.3$ & $23.0 \pm 0.1$ & 0.011 .2 \\
\hline
\end{tabular}

${ }^{a}$ Data from Hayes and Meyer (1989).

"TTX injections every 2-3 d to continuously eliminate impulse transmission (see Materials and Methods).

c Pooled normal regeneration and sham injection data.

${ }^{d}$ Citrate carrier buffer injections intraocularly every $2-3 \mathrm{~d}$. 


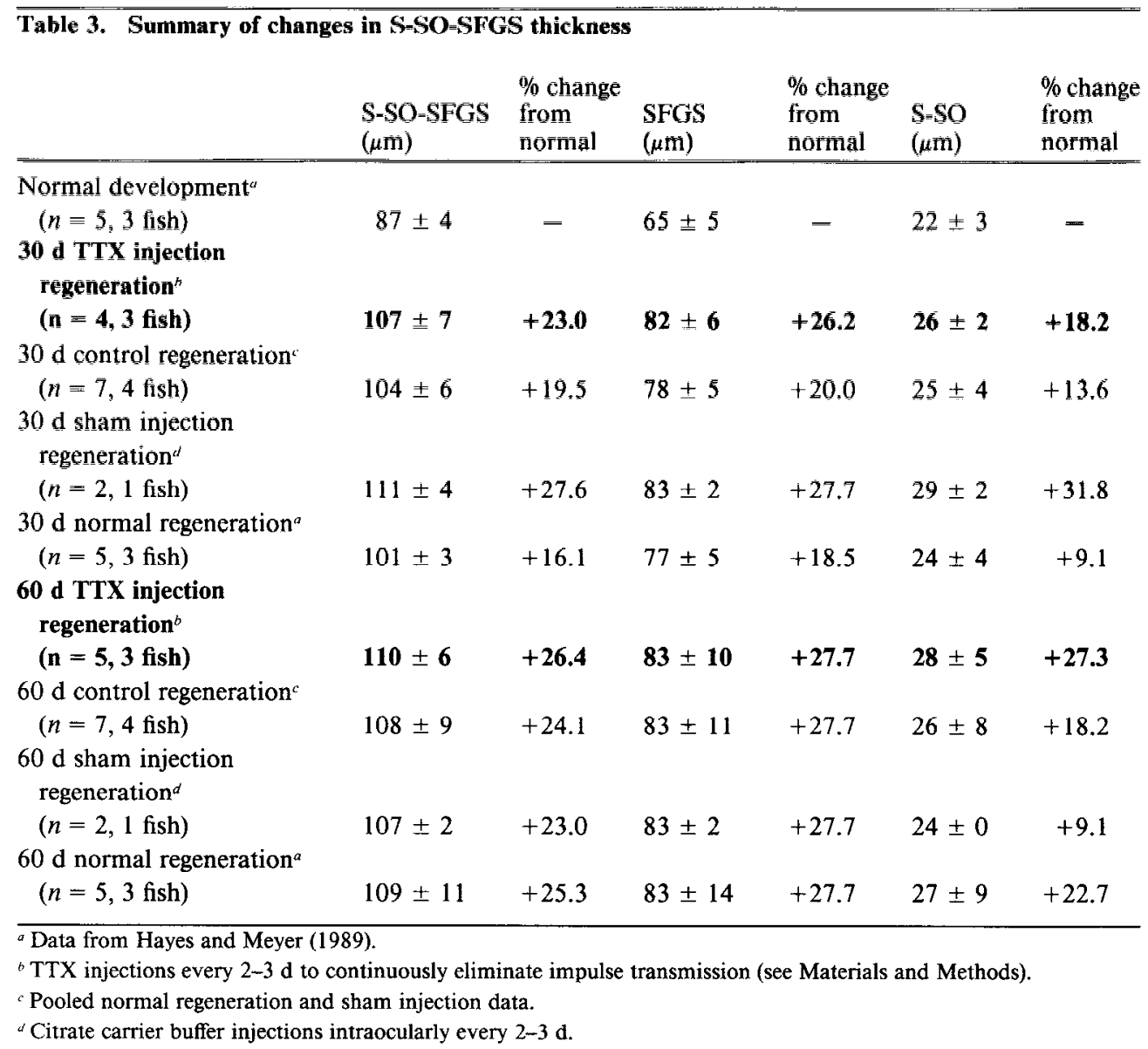

\section{Proliferation and elimination of optic fibers during impulse blockade}

Present findings showed that neither the normal 10-fold increase in the number of optic fibers at $30 \mathrm{~d}$ nor the subsequent $50 \%$ decrease by $60 \mathrm{~d}$ was affected by TTX impulse blockade. Fasciculation and remyelination were also unaffected. These findings contrast with the conclusions of previous electrophysiological and light microscopic studies in this system that intraocular TTX decreases the number, diameter, or myelination of optic fibers in this system (Edwards and Grafstein, 1983; Schmidt et al., 1983). These conclusions were based on the increased latency of field potentials elicited by optic nerve shock (Schmidt et al., 1983), a reduction in the number of axons detectable in silver-stained sections using light microscopy, and reduced axonally transported protein (Edwards and Grafstein, 1983). Present data provide no support for these inferences and lead to the suggestion that the measures used in these previous studies may not be a reliable indicator of fiber maturation.

The dramatic reduction in the number of optic fibers between 30 and $60 \mathrm{~d}$ regeneration indicates that the withdrawal of exuberant optic fibers from tectum is an intrinsic behavior exhibited by retinal ganglion cells. This reduction is most likely a result of reduced branching since retinal ganglion cell death does not occur during impulse blockade (Edwards and Grafstein, 1983). This suggests that retinal ganglion cells that may have extended abnormally large arbors during early regeneration up to $30 \mathrm{~d}$ (Meyer et al., 1985; Rankin and Cook, 1986) subsequently become unable to maintain these exuberant fibers, which are, thus, retracted between 30 and $60 \mathrm{~d}$ by a process that occurs regardless of impulse transmission (Hayes and Meyer, 1989). Correlated with this fiber elimination is the reduction in axoplasmic transport between 36 and $45 \mathrm{~d}$ regeneration that occurs with or without TTX (Edwards and Grafstein, 1983). This reduction may be directly related to the elimination of optic fibers.

The fact that fiber remodeling is coincident with the main activity-sensitive period but is not quantitatively regulated by activity leads to a possible explanation for the existence of an activity-sensitive period; namely, during this period, optic fibers are undergoing large-scale structural changes that occur independently of activity but that can be patterned by activity. In other words, activity can direct the pattern of remodeling during the period in which remodeling is occurring but may not be able to regulate the time of its occurrence or its extent. A similar coincidence may underlie the "critical period" in the developing mammalian visual system when synaptic connections are susceptible to modified visual experience, visual deprivation, and impulse blockade (Chapman et al., 1986; Dubin et al., 1986; Stryker and Harris, 1986).

Activity regulates the topographic pattern of optic synapses but not their quantity

The finding that impulse blockade has no effect on the proliferation and subsequent reduction of sampled optic fibers and no effect on the number of optic synapses dictates constraints on the structural changes that underlie the inhibition of retinotopic refinement (Meyer, 1983; Schmidt and Edwards, 1983). This most likely means that the total length (shaft plus branches) 
30 Days

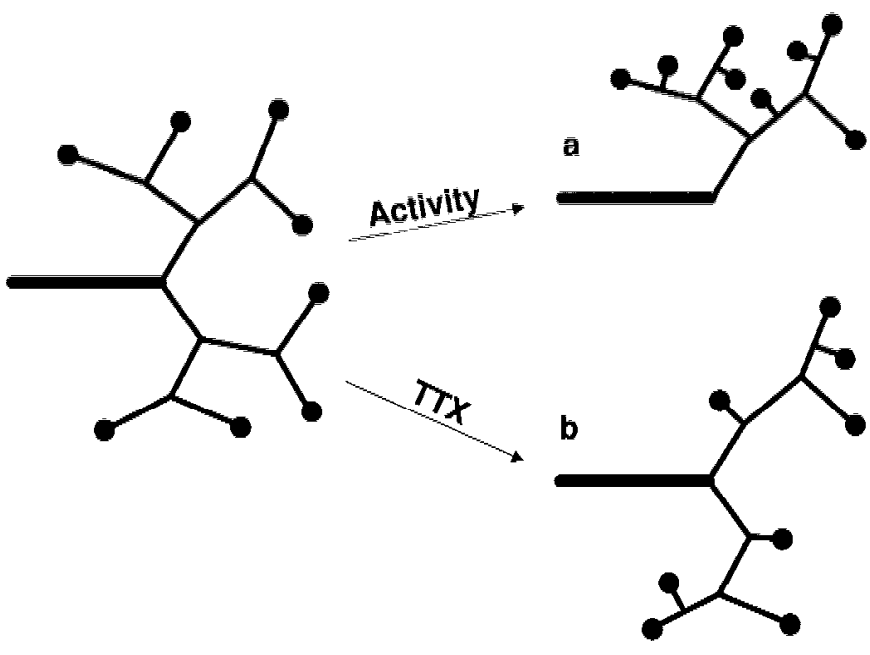

Figure 6. Model for optic regeneration with $(a)$ and without $(b)$ impulse activity. The branched structures represent an idealized arbor of a single retinal ganglion cell making synapses; each circle represents many synapses, which are presumed to be evenly distributed on all branches. $a$. Regeneration with activity. A fiber quickly forms its normal number of synapses before map refinement at $30 \mathrm{~d}$. At $60 \mathrm{~d}$, when map refinement is largely complete, collaterals are eliminated. The fiber forms the same number of synapses but these are now more closely spaced, so the arbor is smaller (see Hayes and Meyer, 1989). $b$, Effect of TTX. Branching and synaptogenesis by each fiber is unaffected by impulse blockade at $30 \mathrm{~d}$. At $60 \mathrm{~d}$, collaterals are climinated and the normal number of synapses remains, but these are more widely distributed. As a result, the arbor is large but has fewer branches than at $30 \mathrm{~d}$.

of each retinal ganglion cell arbor is larger than normal at $30 \mathrm{~d}$ and then decreases by $60 \mathrm{~d}$ to the same degree regardless of activity. With activity, this fiber remodeling is accompanied by spatial convergence of synapses from neighboring ganglion cells onto a small region of tectum. Without activity, this convergence is inhibited (Meyer, 1987; see also Cook and Rankin, 1986).

We propose the following ultrastructural correlates are associated with these events. In early regeneration, ganglion cells have abnormally large arbors with many branches that are distributed over a much larger than normal area of tectum (Fig. 6), as indicated from fiber fills (Meyer, 1980; Cook, 1983; Meyer et al., 1985; Rankin and Cook, 1986). Since relatively little activity-dependent ordering is measurable at $30 \mathrm{~d}$, there is presumably little difference between regeneration with and without activity at this time (Fig. 6, $a, b$; Rankin and Cook, 1986; see also Cook and Rankin, 1986). We suggest that during the period of fiber remodeling, correlated activity from neighboring ganglion cells normally leads to a convergence of these fibers onto neighboring tectal cells, particularly as these also have locally correlated activity (Meyer and Brink, 1988). As a result, the terminals come to occupy a small area of tectum so that each ganglion cell forms a small highly branched arbor (Fig. 6a; Meyer et al., 1985; Rankin and Cook, 1986). However, under TTX blockade, the spatial restriction generated by activity cannot occur and consequently the arbors are abnormally large (Meyer, 1987; see also Cook and Rankin, 1986), although smaller than at $30 \mathrm{~d}$ due to the net reduction in axonal length. In this case, each ganglion cell forms a larger than normal, regenerated arbor that must be less densely branched than nor- mal (Fig. 6b), since the total length of axoplasm is the same as found at $60 \mathrm{~d}$ of normal regeneration.

Taken together, these findings are consistent with the idea that impulse activity directs the patteming of optic fibers viśal=vis functional synāpsés (see Prestige and Willshaw, 1975; Changeux and Danchin, 1976; Willshaw and von der Malsburg, 1976; Whitelaw and Cowan, 1981). Possibly, activity provides an instructive signal (Stent, 1973) that directs the elimination of inappropriately projecting optic fibers (and synapses), thereby allowing the formation of specific synapses by localized sprouting.

\section{References}

Adams, J. C. (1981) Heavy metal intensification of DAB-based HRP reaction product. J. Histochem. Cytochem. 29: 775.

Boss, V. C, and J. T. Schmidt (1984) Activity and the formation of ocular dominance patches in dually innervated tectum of goldfish. $J$. Neurosci. 4: 2891-2905.

Brown, $M_{*} C_{\text {, }}$ and $\mathrm{R}$. Ironton (1977) Motor neurone sprouting induced by prolonged tetrodotoxin block of action potentials. Nature 265 : $459-461$.

Changeux, J.-P., and A. Danchin (1976) Selective stabilization of developing synapses as a mechanism for the specification of neuronal networks. Nature 264: 705-711.

Chapman, B., M. D. Jacobson, H. O. Reiter, and M. P. Stryker (1986) Ocular dominance shift in kitten visual cortex caused by electrical imbalance in retinal activity. Nature $324: 154-156$.

Cook, J. E. (1983) Tectal paths of regenerated optic axons in the goldfish: Evidence from retrograde labeling with HRP. Exp. Brain Res. 51: 433-442.

Cook, J. E., and E. C. C. Rankin (1986) Impaired refinement of the regenerated retinotectal projection of the goldfish in stroboscopic light: A quantitative WGA-HRP study. Exp. Brain Res. 63: 421-430.

Dubin, M. W., L. A. Stark, and S. M. Archer (1986) A role for actionpotential activity in the development of neuronal connections in the kitten retinogeniculate pathway. J. Neurosci. 6: 1021-1036.

Edwards, D. L., and B. Grafstein (1983) Intraocular tetrodotoxin in goldfish hinders optic nerve regeneration. Brain Res. 269: 1-14.

Edwards, D. L., and B. Grafstein (1984) Intraocular injection of tetrodotoxin in goldfish decreases fast axonal transport of $\left({ }^{3} \mathrm{H}\right)$ glucosamine-labeled materials in optic axons. Brain Res. 299: 190-194.

Edwards, D. L., and B. Grafstein (1986) Intraocular tetrodotoxin reduces axonal transport and transcellular transfer of adenosine and other nucleosides in the visual system of goldfish. Brain Res. 364 . 258-267.

Fawcelt, J. W., D. D. M. O'Leary, and M. W. Cowan (1984) Activity and the control of ganglion cell death in the rat retina. Proc. Natl. Acad. Sci. USA 81: 5589-5593.

Harris, W. A. (1980) The effects of eliminating impulse activity on the development of the retinotectal projection in salamanders. J. Comp. Neurol. 194: 303-317.

Harris, W. A. (1981) Neural activity and development. Annu. Rev. Physiol. 43: 689-710.

Hayes, W. P., and R. L. Meyer (1986) Retinotectal synapse numbers are regulated by an activity-independent and target-dependent mechanism in goldfish. Soc. Neurosci. Abstr. 12: 436.

Hayes, W. P., and R. L. Meyer (1988a) Retinotopically inappropriate synapses of subnormal density formed by misdirected optic fibers in goldfish tectum. Dev. Brain Res. 38: 304-312.

Hayes, W. P., and R. L. Meyer (1988b) Normal and regenerating optic fibers in goldfish tectum: HRP-EM evidence for rapid synaptogenesis and optic fiber-fiber affinity. J. Comp. Neurol. 274: 516-538.

Hayes, W. P., and R. L. Meyer (1988c) Optic synapse number but not density is constrained during regeneration on to surgically halved tectum in goldfish: HRP-EM evidence that optic fibers compete for fixed numbers of postsynaptic sites on tectum. J. Comp. Neurol. 274: 539559.

Hayes, W. P., and R. L. Meyer (1989) Normal numbers of retinotectal synapses during the activity-sensitive period of optic regeneration in goldfish: HRP-EM evidence implicating synapse rearrangement and collateral elimination during map refinement. J. Neurosci. 9: 14001413.

Kalil, R. E., M. W. Dubin, G. Scott, and L. A. Stark (1986) Elimination 
of action potentials blocks the structural development of retinogeniculate synapses. Nature $323: 156=158$.

Kuppermann, B, D, and T, Kasamatsu (1983) Changes in geniculate cell size following brief monocular blockade of retinal activity in kittens. Nature 306: 465-468.

Meyer, R. L. (1980) Mapping the normal and regenerating retinotectal projection of goldfish with autoradiographic methods. J. Comp. Neurol. $189: 273=289$.

Meyer, R. L. (1982) Tetrodotoxin blocks the formation of ocular dominance columns in goldfish. Science $218: 589=591$.

Meyer, R. L. (1983) Tetrodotoxin inhibits the formation of refined retinotopography in goldfish. Dev, Brain Res. 6:293-298.

Meyer, R. L. (1987) Intratectal targeting by optic fibers in goldfish under impulse blockade. Dev. Brain Res. 37: 115-124.

Meyer, R. L., and D. L. Brink (1988) Locally correlated activity in the goldfish tectum in the absence of optic innervation. Dev. Brain Res. 41: 25-36.

Meyer, R. L., K. Sakurai, and E. Schauwecker (1985) Topography of regenerating optic fibers in goldfish traced with local wheat germ injections into retina: Evidence for discontinuous microtopography in the retinotectal projection. J. Comp. Neurol. 239: 27-43.

Murray, M., S. Sharma, and M. A. Edwards (1982) Target regulation of synaptic number in the compressed retinotectal projection of goldfish. J. Comp. Neurol. 209: 374-385.

Nelson, P. G. and D. E. Brenneman (1982) Electrical activity of neurons and the development of the brain. Trends Neurosci. 5: 229232.

O'Leary, D. D. M., J. W. Fawcett, and W. M. Cowan (1986) Topographic targeting errors in the retinocollicular projection and their elimination by selective cell death. J. Neurosci. 6: 3692-3705.

Prestige, M. C., and D. J. Willshaw (1975) On a role for competition in the formation of patterned neural connections. Proc. R. Soc. London [Biol.] 190: 77-98.

Rankin, E. C. C., and J. E. Cook (1986) Topographic refinement of the regenerating retinotectal projection of the goldfish in standard laboratory conditions: A quantitative WGA-HRP study. Exp. Brain Res. 63: 409-420.

Reh, T. A., and M. Constantine-Paton (1985) Eye-specific segregation requires neural activity in three-eyed Rana pipiens. J. Neurosci. 5: $1132-1143$.

Riccio, R. V., and M. A. Matthews (1985a) Effects of intraocular tetrodotoxin on dendritic spines in the developing rat visual cortex: A Golgi analysis. Dev. Brain Res. 19: 173-182.

Riccio, R. V., and M. A. Matthews (1985b) The postnatal development of the rat primary visual cortex during optic nerve impulse blockade by intraocular tetrodotoxin: A quantitative electron microscopic analysis. Dev. Brain Res. 20: 55=68.

Ríccio, R. V., and M. A. Matthews (1985c) The effect of intraocular injection of tetrodotoxin on fast axonal transport of $\left({ }^{3} \mathrm{H}\right)$ proline $=$ and ( ${ }^{3}$ H) fucose-labeled materials in the developing rat optic nerve. Neuroscience $16: 1027-1039$.

Schmidt, J. T., and D. L. Edwards (1983) Activity sharpens the map during the regeneration of the retinotectal projection in goldfish. Brain Res. 269: 29-39.

Schmidt, J. T., D. L. Edwards, and C. Stürmer (1983) The re-establishment of synaptic transmission by regenerating optic axons in gold fish: Time course and effects of blocking activity by intraocular injection of tetrodotoxin. Brain Res. 269: 15-27.

Sperry, R. W. (1963) Chemoaffinity in the orderly growth of nerve fiber patterns and connections. Proc. Natl. Acad. Sci. USA 50: $703-$ 710.

Stent, G. S. (1973) A physiological mechanism for Hebb's postulate of learning. Proc. Natl. Acad. Sci. USA 70: 997-1001.

Stryker, M. P., and W. A. Harris (1986) Binocular impulse blockade prevents the formation of ocular dominance columns in cat visua cortex. J. Neurosci. 6: 2117-2133.

Stürmer, C. A. O., and S. S. Easter (1984) A comparison of the normal and regenerated retinotectal pathways of goldfish. J. Comp. Neurol. 223: $57-76$.

Thompson, W. (1985) Activity and synapse elimination at the neuromuscular junction. Cell. Mol. Neurobiol. 5: 167-182.

Van Huizen, F., H. J. Romijn, and A. M. M. C. Habets (1985) Synaptogenesis in rat cerebral cortex cultures is affected during chronic blockade of spontaneous bioelectric activity by tetrodotoxin. Dev. Brain Res. 19: 67-80.

Whitelaw, V. A., and J. D. Cowan (1981) Specificity and plasticity of retinotectal connections: A computational model. J. Neurosci. 1: 13691387.

Willshaw, D. J., and C. von der Malsburg (1976) How patterned connections can be set up by self-organization. Proc. R. Soc. London [Biol.] 194: 431-445. 